\title{
A numerical model to evaluate formation properties through pressure-transient analysis with alternate polymer flooding
}

\author{
Jia Zhang, Shiqing Cheng ${ }^{\circledR *}$, Changyu Zhu, Le Luo \\ College of Petroleum Engineering, China University of Petroleum, Beijing 102249, P. R. China
}

(Received November 30, 2018; revised December 25, 2018; accepted December 28, 2018; available online January 5, 2019)

\section{Citation:}

Zhang, J., Cheng, S., Zhu, C., Luo, L. A numerical model to evaluate formation properties through pressure-transient analysis with alternate polymer flooding. Advances in Geo-Energy Research, 2019, 3(1): 94-103, doi:

10.26804/ager.2019.01.08.

Corresponding author:

*E-mail: chengsq973@163.com

Keywords:

Alternate polymer flooding three-zone composite model pressure transient analysis type-curve matching

\begin{abstract}
:
A numerical pressure transient analysis method of composite model with alternate polymer flooding is presented, which is demonstrated by field test data provided by China National Petroleum Corporation. Polymer concentration distribution and viscosity distribution are obtained on the basis of polymer rheological model, considering shear effect, convection, diffusion, inaccessible pore volume and permeability reduction of polymer. Pressure analysis mathematical model is established by considering wellbore storage effect and skin effect. Type curves are then developed from mathematical model which have seven sections and parameter sensitivity is analyzed, among which the transient sections of lowconcentration and high-concentration hydrolyzed polyacrylamides (HPAM) solution, highconcentration HPAM solution and crude oil show obvious concave shape on pressure derivative curve due to different viscosities of three zones. Formation parameters and viscosity distribution of polymer solution can be calculated by type-curve matching. The polymer flooding field tests prove that the three-zone composite model can reasonably calculate formation parameters in onshore oilfield with alternate polymer flooding, which demonstrate the application potential of the analysis method.
\end{abstract}

\section{Introduction}

Over the past several years, many enhanced oil recovery (EOR) methods were researched in laboratories and oilfields to improve oil recovery (Jamaloei et al., 2010; Yu et al., 2010; Ren et al., 2011; Bera et al., 2013; Farajzadeh et al., 2013; Shiran and Skauge, 2013; Ren et al., 2014; Zhang et al., 2015). However, polymer flooding is most commonly applied in oilfields, especially hydrolyzed polyacrylamides (HPAM) polymer flooding because of its low cost and high efficiency (Wyatt et al., 2011). High sweep efficiency is significant advantage of polymer flooding (Lake, 1989). There comes problems with long-term high-concentration polymer flooding: The great injection pressure, blocking up in the porous medium, which lead to change of reservoir characteristics. In order to improve the efficiency of polymer flooding, alternate flooding of high-concentration and low-concentration polymer solutions has been widely applied in reservoirs. However, mechanism study and pressure analysis models about this technology are scare. On the other hand, pressure analysis methods applied in water flooding reservoirs have been widely developed, however, study of which applied in onshore reservoirs with alternate polymer flooding is still in the primary stage. Liu (1994) analyzes transient pressure behavior in a polymer flooding composite reservoir by considering wellbore storage effect and skin effect. Song $(1996,1997)$ develops pressure analysis models of Newtonian and non-Newtonian fluid composite oilfields and power law non-Newtonian fluid composite oilfields. This paper will discuss the application of pressure analysis model with alternate flooding of highconcentration and low-concentration HPAM solutions in onshore oilfield on the basis of composite model and threezone composite model of polymer flooding (Yu et al., 2014; Zhu et al., 2017). According to the injection process, highconcentration HPAM solution is injected at the beginning, after a period of time, low-concentration HPAM solution is injected. Surrounding the injection well, the first zone is low-concentration HPAM solution, the second zone is highconcentration HPAM solution, the third zone is oil (Fig. 1).

HPAM solution is non-Newtonian fluid widely used in polymer flooding, the viscosity of which is significant to establish pressure transient analysis model. Many researchers 


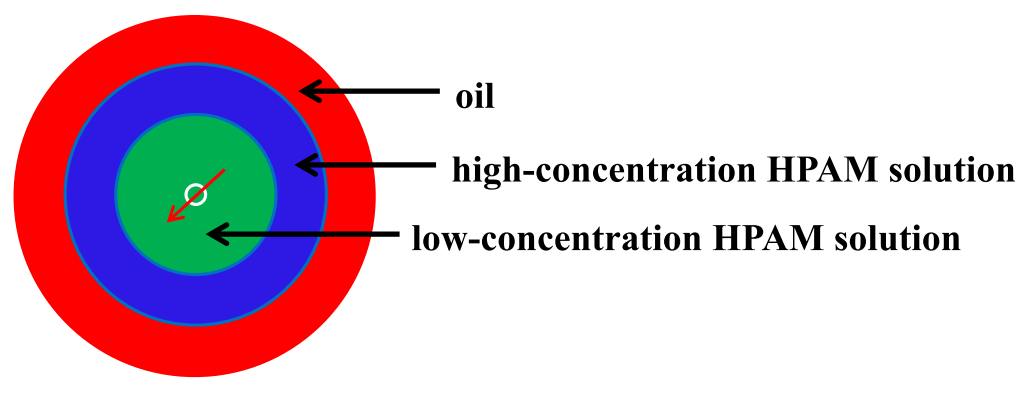

Fig. 1. Physical model of alternate flooding of high-concentration and low-concentration HPAM solutions.

Table 1. Characteristics of the proprietary HPAM polymer solution provided by CNPC.

\begin{tabular}{lllll}
\hline$\mu_{w}(\mathrm{mPa} \cdot \mathrm{s})$ & $A_{1}(\mathrm{mg} / \mathrm{L})^{-1}$ & $A_{2}(\mathrm{mg} / \mathrm{L})^{-2}$ & $A_{3}(\mathrm{mg} / \mathrm{L})^{-3}$ & $D\left(\mathrm{~cm}^{2} / \mathrm{s}\right)$ \\
\hline 0.5 & 6.34 & 1.93 & 9.21 & 0.0246 \\
\hline
\end{tabular}

simply consider HPAM solution as power law fluid with constant power exponent model in polymer flooding oilfields (Zhang et al., 2010; Veerabhadrappa et al., 2013), which ignores interaction between polymer and reservoir rock, diffusion and convection of polymer. Meanwhile, the adsorption of polymer in formation porosity leads to inaccessible pore volume (IPV) (Liu et al., 2012) and permeability reduction, which also need to be taken into account. This paper establishes numerical method and analysis technology of three-zone composite model suitable for onshore oilfields with alternate polymer flooding, which taking wellbore storage effect, skin effect, convection, diffusion, inaccessible pore volume and permeability reduction into account. Moreover, field test data of alternate polymer flooding are further interpreted by this method.

\section{Polymer rheological study}

\subsection{Rheological model}

A proprietary HPAM used for polymer flooding is provided by China National Petroleum Corporation (CNPC). which is assumed as non-Newtonian fluid. As discussed above, the power law model (Bondor et al., 1972) or Carreau model (Carreau, 1968) both couldn't accurately explain rheological behavior of HPAM solution used in this paper. Polymer shearthinning behavior is expressed by use of Meter equation (Eq. (1)) (Bourdet et al., 1989). The shear-thinning model applied in this paper match the apparent viscosity of proprietary HPAM solution very well provided by CNPC under extensive velocities.

$$
\mu_{p}=\mu_{\infty}+\frac{\mu_{p}^{0}-\mu_{\infty}}{1+\left(\frac{\gamma}{\gamma_{1 / 2}}\right)^{P a-1}}=\mu_{w}+\frac{\mu_{p}^{0}-\mu_{w}}{1+\left(\frac{\gamma}{\gamma_{1 / 2}}\right)^{P a-1}}
$$

where $\mu_{p}$ is viscosity of HPAM solution, $\mathrm{mPa} \cdot \mathrm{s} ; \mu_{\infty}$ is viscosity of HPAM solution at infinite shear rate, $\mathrm{mPa} \cdot \mathrm{s} ; \mu_{w}$ is water viscosity; $\gamma_{1 / 2}$ is the shear rate when polymer viscosity is the mean of $\mu_{\infty}$ and $\mu_{p}^{0}, \mathrm{~s}^{-1} ; \gamma$ is effective shear rate, $\mathrm{s}^{-1} ; P a$ is fitting parameter; $\mu_{p}^{0}$ is the viscosity when shear rate is very low (nearly zero), $\mathrm{mPa} \cdot \mathrm{s}$, which is computed by modificatory Flory-Huggins equation (Flory, 1953):

$$
\mu_{p}^{0}=\mu_{w}\left[1+\left(A_{1} C_{p}+A_{2} C_{p}^{2}+A_{3} C_{p}^{3}\right) C_{S E P}^{S P}\right]
$$

where $A_{1}(\mathrm{mg} / \mathrm{L})^{-1}, A_{2}(\mathrm{mg} / \mathrm{L})^{-2}$, and $A_{3}(\mathrm{mg} / \mathrm{L})^{-3}$ are fitting parameters; $C_{p}$ is polymer concentration, $\mathrm{g} / \mathrm{L} ; C_{S E P}^{S P}$ is coefficient expressing effect of salinity and hardness over polymer viscosity.

The HPAM solutions are disposed by mechanical stirring at $75^{\circ} \mathrm{C}$ which is similar to oilfield temperature. The HPAM concentrations vary from 100 to $4,000 \mathrm{mg} / \mathrm{L}$. The polymer rheological measurement is conducted with Haake RS6000 rheometer. The HPAM viscosities of different concentrations are measured at $75{ }^{\circ} \mathrm{C}$ under $0.01 \mathrm{~s}^{-1}$ shear rate to get the fitting numbers of $A_{1}, A_{2}$, and $A_{3}$, which increase with increasing concentration of polymer solutions (Table 1).

$P a$ and $\gamma_{1 / 2}$ are functions of $\mu_{p}^{0}$ (or polymer concentration). The expressions supplied by CNPC are shown in Eqs. (3) and (4), respectively.

$$
\begin{gathered}
P a=1.163\left(\mu_{p}^{0}\right)^{0.0311} \\
\gamma_{1 / 2}=375.1\left(\mu_{p}^{0}\right)^{-1.378}+0.0356
\end{gathered}
$$

The expressions of effective shear rate and velocity are shown in Eqs. (5) and (6) (Wang, 1990):

$$
\begin{gathered}
\gamma=\frac{3 n+1}{n+1} \frac{10^{4} v}{\sqrt{8 C^{\prime} K \phi}} \\
v=\frac{Q}{2 \pi r h \phi}
\end{gathered}
$$

where $n$ is power law index of HPAM solution; $C^{\prime}$ is oilfield tortuosity coefficient; $\phi$ is oilfield porosity; $K$ is oilfield permeability, $\mu \mathrm{m}^{2} ; Q$ is injection rate of HPAM solution, $\mathrm{m}^{3} / \mathrm{s}$; $h$ is oilfield thickness, $\mathrm{m} ; r$ is radial distance from testing well, $\mathrm{m} ; v$ is simplified Darcy velocity, $\mathrm{m} / \mathrm{s}$. 
Considering inaccessible pore volume and permeability reduction caused by polymer flooding, Eq. (5) is changed to Eq. (7):

$$
\gamma=\frac{3 n+1}{n+1} \frac{10^{4} v}{\sqrt{8 C^{\prime} K_{p} \phi_{p}}}
$$

where $K_{p}$ is effective permeability, $K_{p}=K / R_{k}, K$ is reservoir permeability; $R_{k}$ is permeability reduction coefficient; $\phi_{p}$ is effective porosity, $\phi_{p}=\phi(1-\mathrm{IPV}), \phi$ is porosity, IPV is inaccessible pore volume fraction.

HPAM concentration equation considering effect of convection and diffusion is exhibited in Eq. (8) (Wang, 2008):

$$
C_{p}(r, t)=\frac{C_{p 0}}{2}-\frac{C_{p 0}}{2} \operatorname{erf}\left[\frac{r-v t}{2 \sqrt{D t}}\right]
$$

where $C_{p 0}$ is initial polymer concentration, $\mathrm{g} / \mathrm{L} ; D$ is diffusion coefficient of $\mathrm{HPAM}, \mathrm{cm}^{2} / \mathrm{s} ; \operatorname{erf}$ is error function; $t$ is seepage time, $s$.

\subsection{Polymer concentration distribution}

When injection time $\left(t_{p}\right)$ and injection rate $(Q)$ of polymer solution are constant, polymer concentration ratio $\left(C_{p} / C_{p 0}\right)$ keeps high level in near-wellbore region, and drops dramatically with increasing radial distance (Figs. 2 and 3). Region of high-concentration ratio expands with increasing injection time (Fig. 2) or increasing injection rate (Fig. 3) of polymer solution.

\subsection{Polymer viscosity distribution}

According to the rheological model mentioned above, viscosity of polymer solution decreases with increasing effective shear rate, which is called polymer shear thinning, increases with increasing injection polymer concentration (Fig. 4). When injection polymer concentration, injection time and injection rate of polymer solution are constant, polymer solution viscosity increases firstly due to high shear rate in near-wellbore region and then decreases dramatically because of low-concentration in far-wellbore region. High viscosity region expands with increasing injection time or increasing injection rate due to accumulation of polymer, region of polymer shear thinning enlarges caused by increasing injection rate (Figs. 5 and 6).

\section{Pressure analysis modeling methodology}

Based on the rheological model and composite model discussed above (Zhu and Cheng, 2017), the pressure analysis interpretation model in composite reservoir with alternate polymer flooding is established, taking shear effect, diffusion, convection, inaccessible pore volume and permeability reduction of polymer, wellbore storage effect and skin effect into account. Mathematical model is written as Eq. (9) to Eq. (19).

The first zone:

$$
\frac{1}{r} \frac{\partial}{\partial r}\left(r \frac{1}{\mu_{p 1}} \frac{\partial p_{1}}{\partial r}\right)=\left(\frac{\phi_{1} C_{t 1}}{K_{1}}\right) \frac{\partial p_{1}}{\partial t}\left(0<r \leqslant r_{m 1}\right)
$$

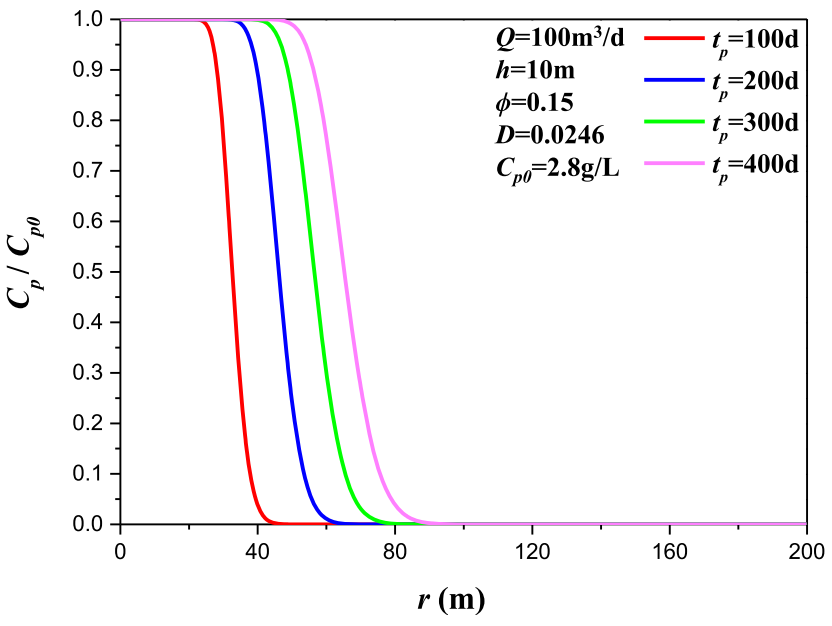

Fig. 2. Effect of injection time of polymer solution on polymer concentration distribution.

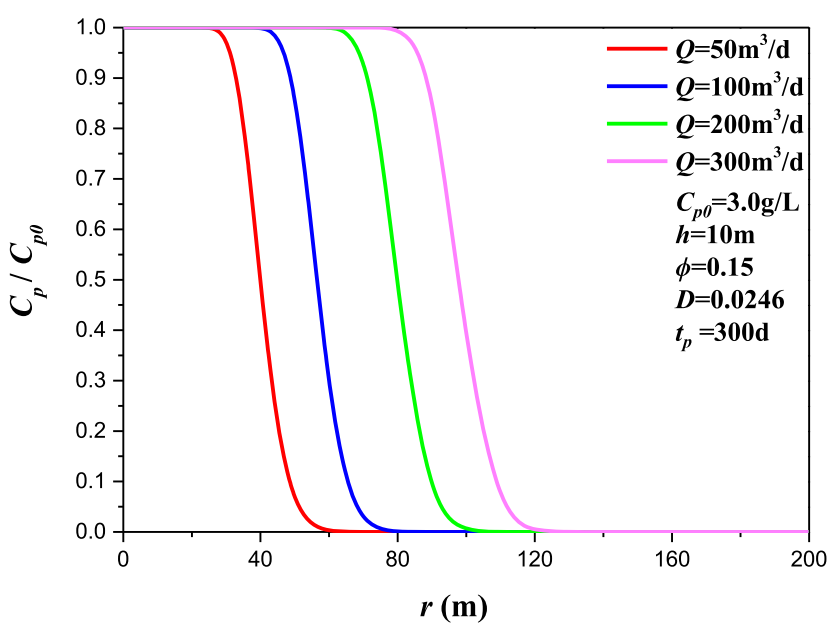

Fig. 3. Effect of injection rate of polymer solution on polymer concentration distribution.

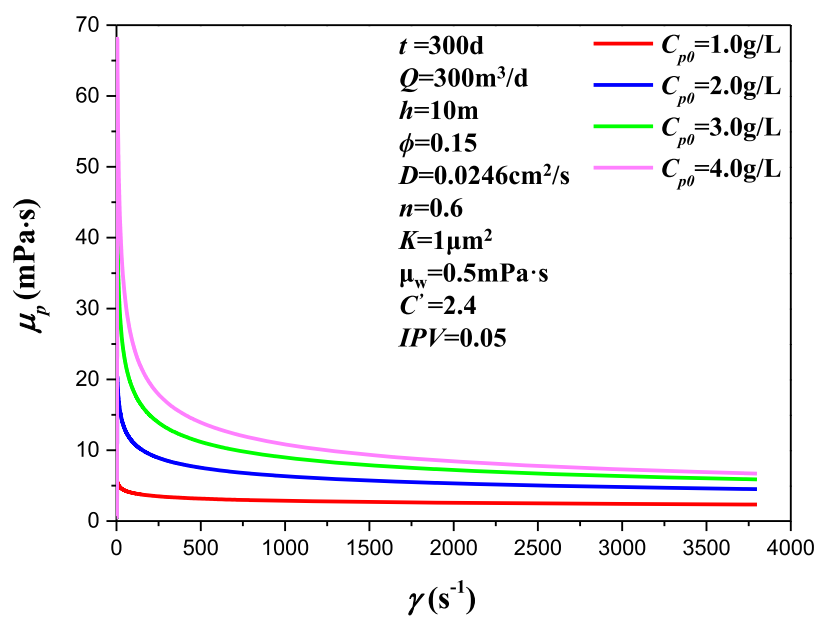

Fig. 4. Effect of injection concentration and effective shear rate of polymer solution on polymer viscosity. 


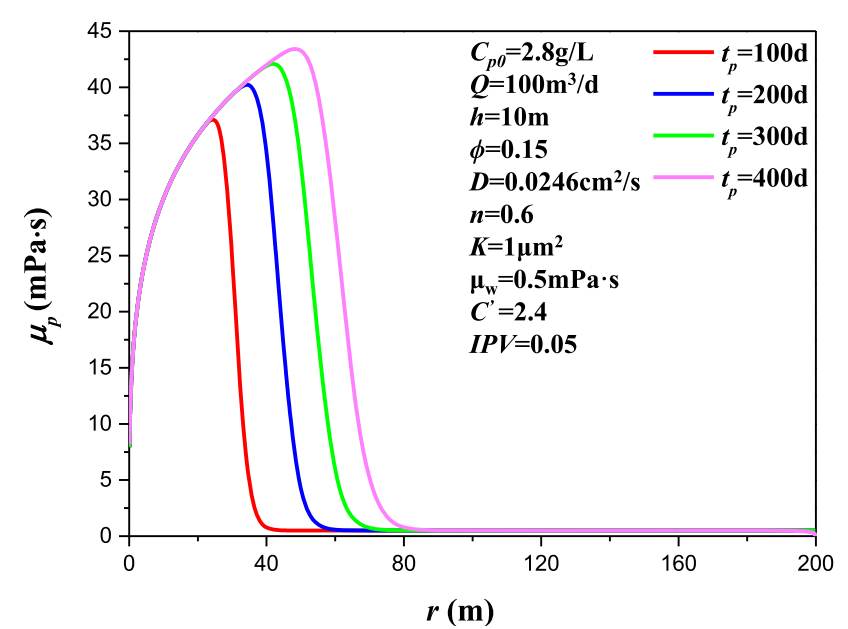

Fig. 5. Effect of injection time of polymer solution on polymer viscosity distribution.

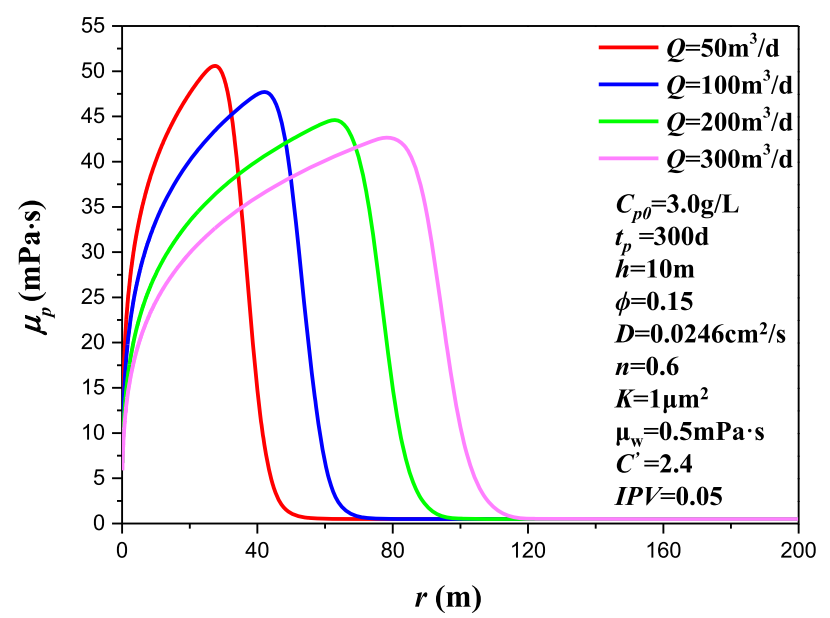

Fig. 6. Effect of injection rate of polymer solution on polymer viscosity distribution.

The second zone:

$\frac{1}{r} \frac{\partial}{\partial r}\left(r \frac{1}{\mu_{p 2}} \frac{\partial p_{2}}{\partial r}\right)=\left(\frac{\phi_{2} C_{t 2}}{K_{2}}\right) \frac{\partial p_{2}}{\partial t}\left(r_{m 1}<r \leqslant r_{m 2}\right)$

The third zone:

$$
\frac{1}{r} \frac{\partial}{\partial r}\left(r \frac{\partial p_{3}}{\partial r}\right)=\mu_{0}\left(\frac{\phi_{3} C_{t 3}}{K_{3}}\right) \frac{\partial p_{3}}{\partial t}\left(r>r_{m 2}\right)
$$

Internal boundary conditions:

$$
\begin{gathered}
Q B=C \frac{d p_{w f}}{d t}-\left(\frac{2 \pi r K_{1} h}{\mu_{p 1}} \frac{\partial P_{1}}{\partial r}\right)_{r=r_{w}} \\
p_{w f}-\left.p\right|_{r=r_{w}}=-S\left(r \frac{\partial p_{1}}{\partial r}\right)_{r=r_{w}}
\end{gathered}
$$

External boundary condition (infinite boundary):

$$
p_{3}(r \rightarrow \infty, t)=p_{i}
$$

At interface:

$$
\begin{gathered}
p_{1}\left(r=r_{m 1}, t\right)=p_{2}\left(r=r_{m 1}, t\right) \\
p_{2}\left(r=r_{m 2}, t\right)=p_{3} \quad\left(r=r_{m 2}, t\right) \\
\frac{K_{1}}{\mu_{p 1}} \frac{\partial p_{1}}{\partial r}\left(r=r_{m 1}, t\right)=\frac{K_{2}}{\mu_{p 2}} \frac{\partial p_{2}}{\partial r} \quad\left(r=r_{m 1}, t\right) \\
\frac{K_{2}}{\mu_{p 2}} \frac{\partial p_{2}}{\partial r}\left(r=r_{m 2}, t\right)=\frac{K_{3}}{\mu_{o}} \frac{\partial p_{3}}{\partial r} \quad\left(r=r_{m 2}, t\right)
\end{gathered}
$$

Initial condition:

$$
p_{1}(r, t=0)=p_{2}(r, t=0)=p_{3}(r, t=0)=p_{i}
$$

where $p_{1}, \phi_{1}, C_{t 1}, K_{1}$ is respectively pressure (MPa), porosity, total compressibility $\left(\mathrm{MPa}^{-1}\right)$, permeability $\left(\mu \mathrm{m}^{2}\right)$ of the first zone; $p_{2}, \phi_{2}, C_{t 2}, K_{2}$ is respectively pressure (MPa), porosity, total compressibility $\left(\mathrm{MPa}^{-1}\right)$, permeability $\left(\mu \mathrm{m}^{2}\right)$ of the second zone; $p_{3}, \phi_{3}, C_{t 3}, K_{3}$ is respectively pressure (MPa), porosity, total compressibility $\left(\mathrm{MPa}^{-1}\right)$, permeability $\left(\mu \mathrm{m}^{2}\right)$ of the third zone; $p_{i}$ is primitive oilfield pressure, MPa; $p_{w f}$ is bottom hole pressure, MPa; $C$ is wellbore storage coefficient, $\mathrm{m}^{3} / \mathrm{MPa} ; B$ is volume factor of polymer solution; $S$ is skin factor; $R_{m 1}$ is radius of the first zone, m; $R_{m 2}$ is radius of the second zone, $\mathrm{m} ; \mu_{p 1}$ is viscosity of low-concentration polymer solution in the first zone, $\mathrm{mPa} \cdot \mathrm{s} ; \mu_{p 2}$ is viscosity of highconcentration polymer solution in the second zone, $\mathrm{mPa} \cdot \mathrm{s} ; \mu_{o}$ is oil viscosity in the third zone, $\mathrm{mPa} \cdot \mathrm{s}$.

Dimensionless parameters are developed to analyze bottom-hole pressure excluding the effect of some oilfield parameters, which is written as Eq. (20) to Eq. (25):

$$
\begin{gathered}
p_{D}=\frac{K h}{1.842 \times 10^{-3} Q \mu_{p 1} B}\left(p-p_{i}\right) \\
p_{w D}=\frac{K h}{1.842 \times 10^{-3} Q \mu_{p 1} B}\left(p_{w}-p_{i}\right) \\
t_{D}=\frac{3.6 K}{\phi \mu_{p 1} C_{t} r_{w}{ }^{2}} t \\
C_{D}=\frac{C}{2 \pi h \phi C_{t} r_{w}{ }^{2}} \\
r_{D}=\frac{r}{r_{w}} \\
p_{w D}^{\prime}=\frac{\Delta p_{w D}}{\Delta t_{D}}
\end{gathered}
$$

where $p_{D}$ is dimensionless pressure; $p_{w D}$ is dimensionless bottom-hole pressure; $p_{w D}^{\prime}$ is derivative of dimensionless bottom-hole pressure; $t_{D}$ is dimensionless time; $\Delta p_{w D}$ is difference of dimensionless bottom-hole pressure; $\Delta t_{D}$ is difference of dimensionless time difference; $C_{D}$ is dimensionless wellbore storage coefficient; $r_{D}$ is dimensionless distance; $r_{w}$ is wellbore radius, $\mathrm{m}$. 


\section{Results and discussion}

\subsection{Formation pressure difference}

The formation pressure grows with increasing injection time of polymer solution during alternate polymer flooding. On the basis of dimensionless pressure difference and dimensionless distance, the curves of pressure difference at different time are obtained. When the radius of first zone is $110 \mathrm{~m}$ and the radius of second zone is $298 \mathrm{~m}$, pressure difference grows with increasing injection time of low-concentration polymer solution and decreases with increasing distance (Fig. 7).

\subsection{Type curves and sensitivity analysis}

On the basis of dimensionless bottom-hole pressure (BHP) and derivative of dimensionless BHP, type curves in log-log scale are obtained, which have seven flow sections (Fig. 8): (I) wellbore storage section; (II) intermediate flow section (transient section), that describes pressure response between wellbore storage stage and first radial flow stage; (III) first radial flow section; (IV) transient section of low-concentration and high-concentration polymer solution, pressure derivative curve of which exhibiting an evident upturn; (V) second radial flow section, pressure derivative curve of which showing a slope due to high-concentration of the HPAM solution; (VI) transient section of high-concentration HPAM solution and oil; (VII) combination section (effected by three zones at the same time).

The effects of various parameters on type curves are analyzed, including injection concentration of polymer solution, radius of first zone, radius of second zone and permeability of every zone.

\subsubsection{Injection concentration of HPAM solution}

The effect of injection concentration of low-concentration HPAM solution on type curves in composite reservoir with alternate polymer flooding is exhibited in Fig. 9. The higher injection concentration of low-concentration HPAM solution is, the larger flow resistance is in first zone, that leading to pressure derivative curve moving up in transient flow section (II) and first radial flow section (III), while other sections are not influenced.

The effect of injection concentration of high-concentration HPAM solution on type curves in composite reservoir with alternate polymer flooding is shown in Fig. 10. The increasing injection concentration of high-concentration HPAM solution leads to pressure derivative curve moving up in transient section (IV), second radial flow section $(\mathrm{V})$, transient section of high-concentration HPAM solution and oil (VI).

\subsubsection{Composite radius}

The effect of first zone radius on type curves in composite reservoir with alternate HPAM solution flooding is exhibited in Fig. 11. The first zone radius manifests injection time of low-concentration HPAM solution and sweeping volume of low-concentration HPAM solution. When second radius keeps

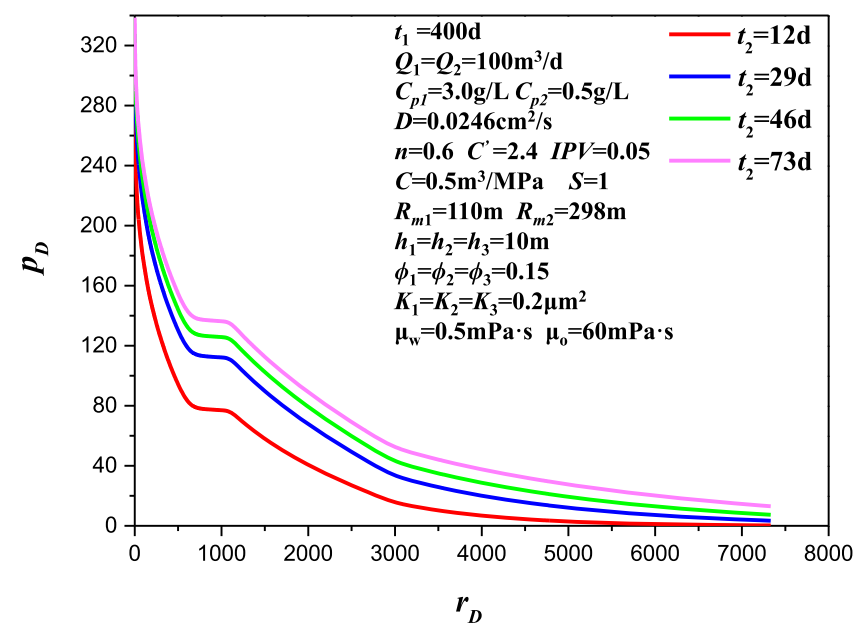

Fig. 7. Effect of injection time of low-concentration polymer solution on pressure difference distribution.

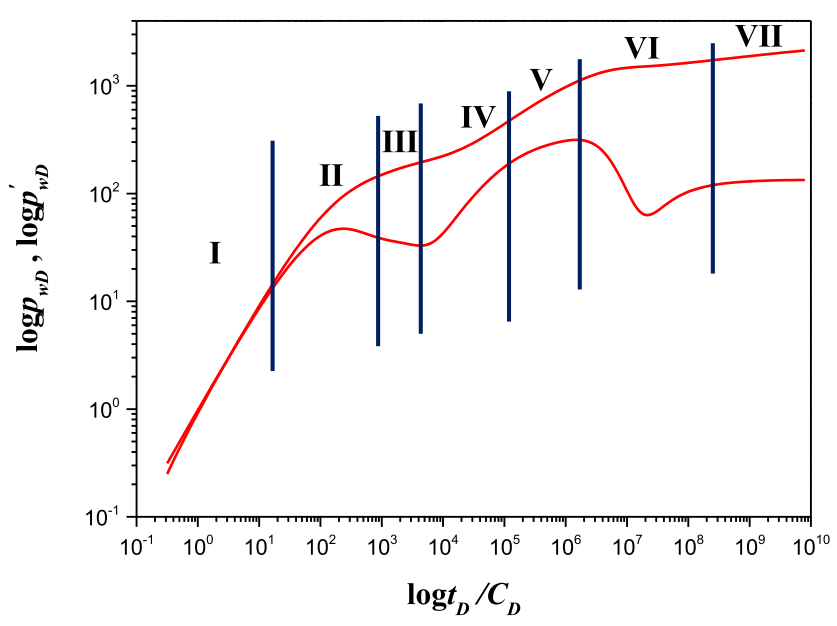

Fig. 8. Type curves of pressure transient analysis in three-zone composite reservoir with alternate HPAM flooding.

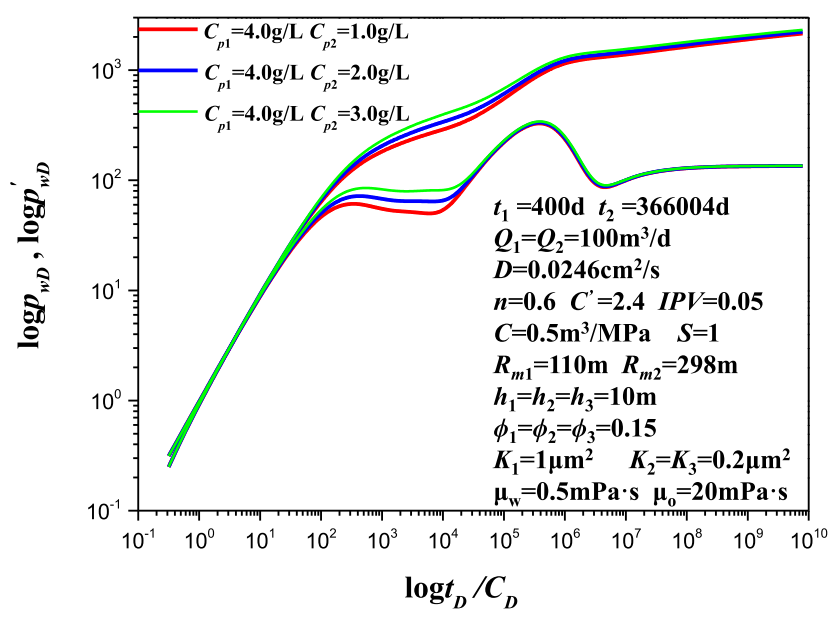

Fig. 9. Effect of injection concentration of low-concentration HPAM solution on type curves. 


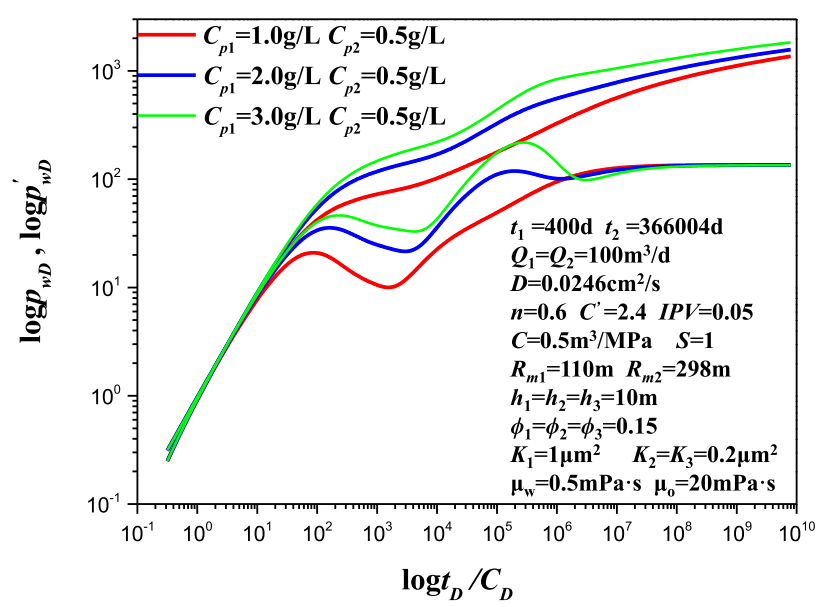

Fig. 10. Effect of injection concentration of high-concentration HPAM solution on type curves.

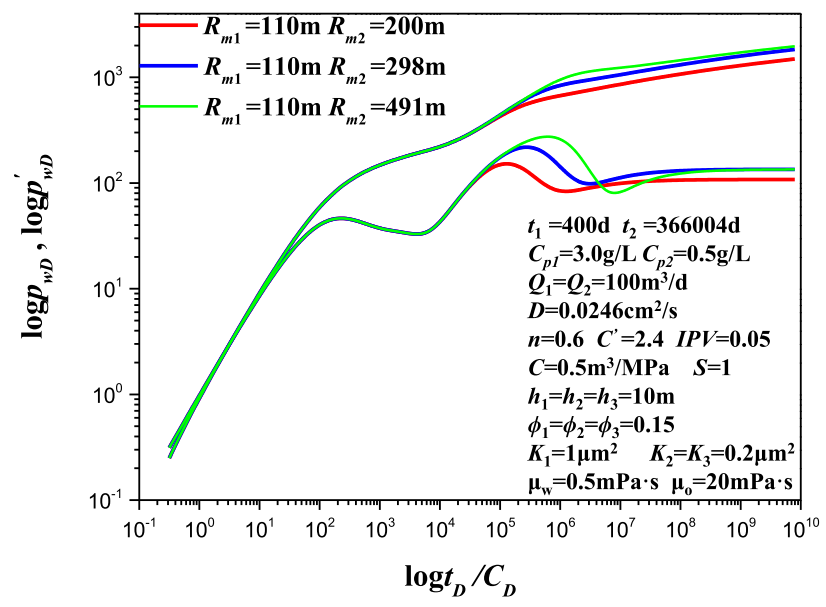

Fig. 12. Effect of the second zone radius on type curves.

invariable, the larger first zone radius is, the longer injection time of first radial flow section (III) is, which resulting in transient section (IV) appearing later. Nevertheless, pressure derivative curves will overlap at last in combination section (VII), because first zone radius do not influence mobility of other regions.

The effect of second zone radius on type curves in composite reservoir with HPAM flooding is exhibited in Fig. 12. The second zone radius manifests injection time of highconcentration HPAM solution and sweeping volume of highconcentration HPAM solution. When first radius keeps invariable, the larger second zone radius is, the longer injection time of second radial flow section $(\mathrm{V})$ is, which causing transient section (VI) emerging later. But pressure derivative curves overlap in first radial flow section (III), intermediate section (IV) and combination section (VII).

\subsubsection{Permeability}

The effect of first zone permeability on typical curves in composite reservoir with HPAM flooding is exhibited in Fig.

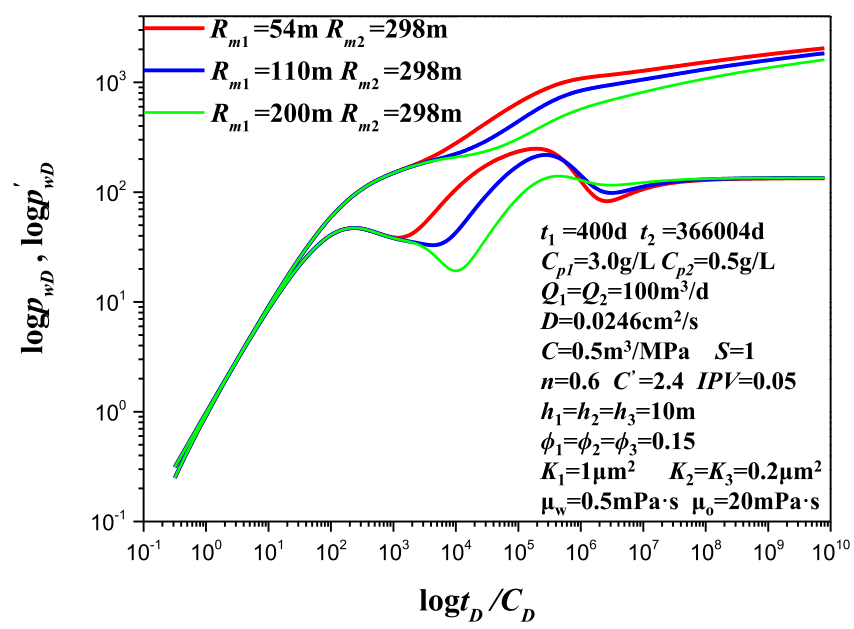

Fig. 11. Effect of the first zone radius on type curves.

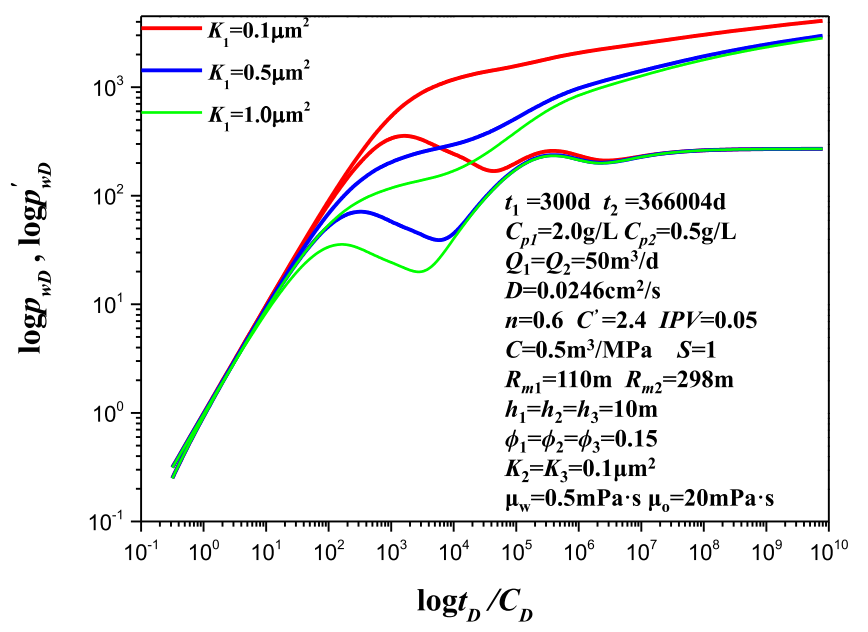

Fig. 13. Effect of first zone permeability on type curves.

13. Pressure curve and pressure derivative curve move downward and emerge early in transient section (II), first radial flow section (III) and transient section (IV) with increasing first zone permeability, which causing pressure loss decreasing. However, pressure derivative curves of other sections keep overlapping, which are not influenced by first zone permeability.

Pressure derivative curve move downward in transient section (IV), second radial flow section (V) and transient section (VI) with increasing second zone permeability, while pressure derivative curves of other sections are convergent (Fig. 14).

Pressure curve and pressure derivative curve move downward in transient section (VI) and combination section (VII) with increasing third zone permeability, while pressure derivative curves of other sections are convergent (Fig. 15).

\section{Field tests interpretation}

Pressure analysis data of field test was provided by CNPC. 


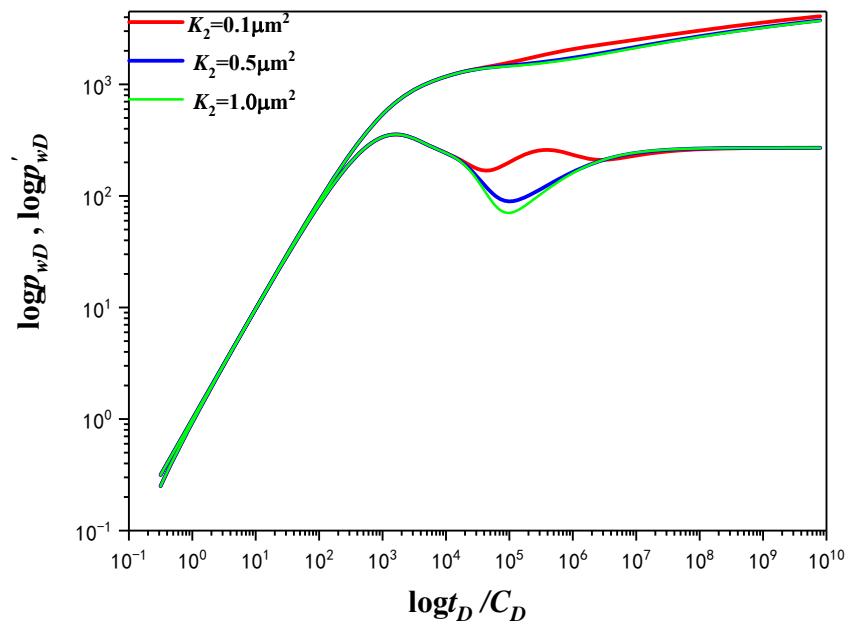

Fig. 14. Effect of second zone permeability on type curves.

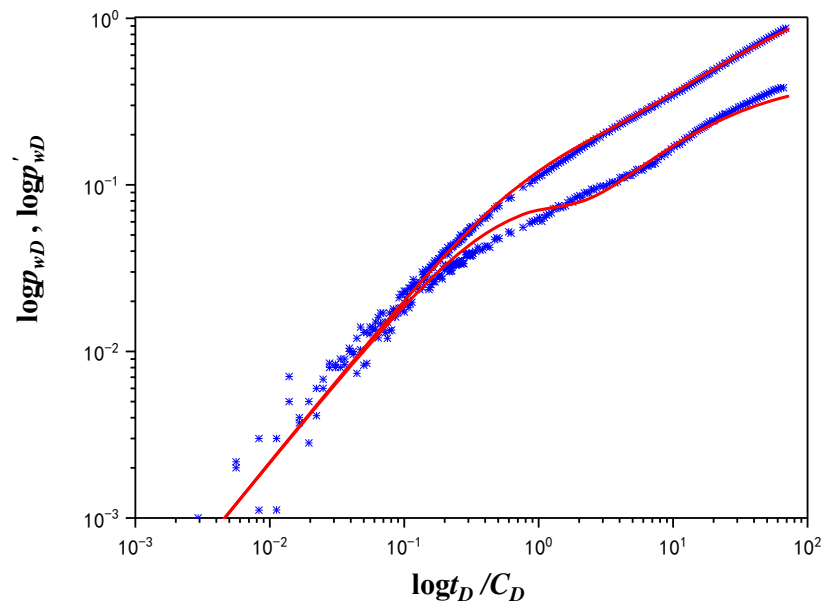

Fig. 16. Well 1 field test data and matching curves.

First draw pressure curve and pressure derivative curve of field test data with time in log-log scale and modify smoothing of curves with Bourdet's method (Yu et al., 2014). Then draw pressure curve and pressure derivative curve with basic oilfield parameters and assuming interpreting parameters using models studied above. Finally, adjust assuming interpreting parameters and perform history matching to get right outcome of threezone composite oilfield with alternate HPAM solution flooding until curves deriving from model and field test data overlapping. In this way, average formation pressure, permeability of every zone, composite radius, skin factor, wellbore storage coefficient and so on would be calculated, which is basis of adjusting development plan.

Well 1 performed HPAM flooding with injection concentration of 1,200 mg/L from Sep. 1, 2014 to Aug. 2, 2015, with injection concentration of $600 \mathrm{mg} / \mathrm{L}$ from Aug. 3, 2015 to Oct. 9, 2015, then polymer injection was stopped and pressures were measured for three days. Well 2 performed HPAM flooding with injection concentration of $1,600 \mathrm{mg} / \mathrm{L}$

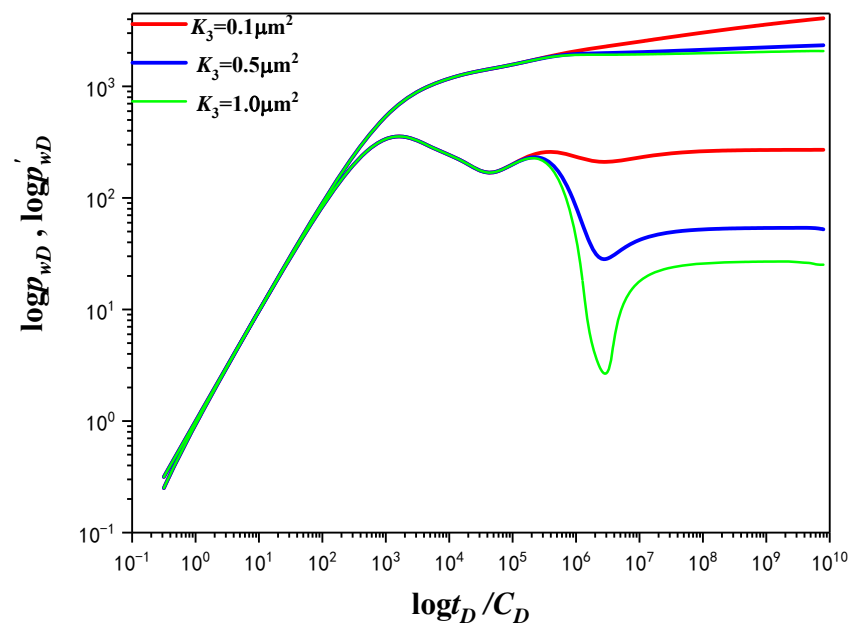

Fig. 15. Effect of third zone permeability on type curves.

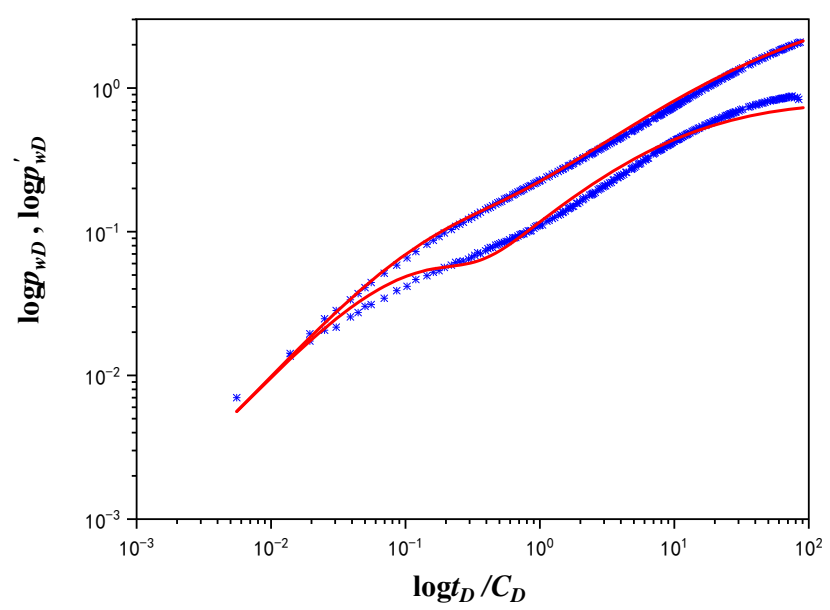

Fig. 17. Well 2 field test data and matching curves.

from Sep. 2, 2015 to Mar. 9, 2017, with injection concentration of $600 \mathrm{mg} / \mathrm{L}$ from Mar. 10, 2017 to Jun. 7, 2017, then polymer injection was ceased and pressures were measured for four days. Basic data of well 1 and well 2 are exhibited in Table 2. Field testing data and matching curves are exhibited in Figs. 16 and 17, interpretation outcomes are exhibited in Table 3. The permeability by interpreting field test data conform to practical oilfield, demonstrating that model presented in this paper could analyze field pressure test and assess formation.

\section{Conclusion}

This work establishes pressure analysis models for threezone composite reservoirs with alternate HPAM flooding. Type curves and sensitivity analysis are accomplished on the basis of numerical solution, at last interpreting parameters are acquired by matching of field test data and type curves. Three conclusions are summarized from the study above.

1) Polymer concentration distribution, viscosity distribution, 
Table 2. Basic parameters of wells and reservoir for field tests.

\begin{tabular}{llll}
\hline Parameters & Units & Well 1 & Well 2 \\
\hline Injection rate & $Q\left(\mathrm{~m}^{3} / \mathrm{d}\right)$ & 34 & 19 \\
Porosity & $\phi$ & 0.158 & 0.158 \\
Crude oil viscosity & $\left.\mu_{o}(\mathrm{mPa} \cdot \mathrm{s})^{-1}\right)$ & 5.84 & 5.84 \\
Total compressibility & $C_{t}\left(\mathrm{MPa}^{-1}\right)$ & 0.002 & 0.002 \\
Well radius & $r_{w}(\mathrm{~m})$ & 0.07 & 0.07 \\
Volume factor & $B_{o}$ & 1.175 & 1.175 \\
Formation thickness & $h$ & 18.5 & 12.5 \\
Permeability before polymer flooding & $K\left(\mu \mathrm{m}^{2}\right)$ & 0.25 & 0.25 \\
\hline
\end{tabular}

Table 3. Interpretation results of well 1 and well 2.

\begin{tabular}{llll}
\hline Parameters & Units & Well 1 & Well 2 \\
\hline Average reservoir pressure & $p_{i}(\mathrm{MPa})$ & 22.41 & 22.74 \\
The first zone permeability & $K_{1}\left(\mu \mathrm{m}^{2}\right)$ & 0.151 & 0.153 \\
The second zone permeability & $K_{2}\left(\mu \mathrm{m}^{2}\right)$ & 0.025 & 0.011 \\
The third zone permeability & $K_{3}\left(\mu \mathrm{m}^{2}\right)$ & 0.021 & 0.009 \\
The first radius & $R_{m 1}(\mathrm{~m})$ & 45.3 & 20.2 \\
The second radius & $R_{m 2}(\mathrm{~m})$ & 150.5 & 241.6 \\
Skin factor & $S$ & 1 & 1 \\
Wellbore storage coefficient & $\mathrm{C}\left(\mathrm{m}^{3} / \mathrm{MPa}\right)$ & 6.49 & 0.74 \\
\hline
\end{tabular}

and the pressure analysis model developed in this work by considering IPV, permeability reduction, shear rate, diffusion, and convection accord with rheological characteristic of HPAM solution provided by CNPC.

2) Sensitivity analysis is performed to study the effect of different parameters on type curves, incorporating injection polymer concentration, composite radius and permeability of every zone.

3) Field tests are conducted in two wells of three-zone composite reservoirs with alternate HPAM flooding. The model presented in this paper is applied to match field test data to obtain interpreting parameters of oilfield, which demonstrates the accuracy of pressure transient analysis method.

\section{Nomenclature}

$\mu_{p}=$ viscosity of HPAM solution, $\mathrm{mPa} \cdot \mathrm{s}$

$\mu_{\infty}=$ viscosity of HPAM solution at infinite shear rate, $\mathrm{mPa} \cdot \mathrm{s}$

$\mu_{w}=$ brine viscosity, $\mathrm{mPa} \cdot \mathrm{s}$

$\mu_{p}^{0}=$ viscosity when shear rate is very low (nearly zero), $\mathrm{mPa} \cdot \mathrm{s}$

$\gamma_{1 / 2}=$ the shear rate when viscosity is mean of $\mu_{\infty}$ and $\mu_{p}^{0}$,

$\gamma=$ effective shear rate, $\mathrm{s}^{-1}$

$P a=$ fitting parameter

$A_{1}=$ fitting parameter, $(\mathrm{mg} / \mathrm{L})^{-1}$

$A_{2}=$ fitting parameter, $(\mathrm{mg} / \mathrm{L})^{-2}$
$A_{3}=$ fitting parameter, $(\mathrm{mg} / \mathrm{L})^{-3}$

$C_{p}=$ polymer concentration, $\mathrm{g} / \mathrm{L}$

$C_{S E P}^{S P}=$ coefficient expresses effect of salinity and hardness over polymer viscosity

$n=$ power law index of HPAM solution

$C^{\prime}=$ oilfield tortuosity coefficient

$\phi=$ oilfield porosity

$K=$ oilfield permeability, $\mu \mathrm{m}^{2}$

$Q=$ injection rate of HPAM solution, $\mathrm{m}^{3} / \mathrm{s}$ $\mathrm{m}^{3} / \mathrm{d}$

$Q 1=$ injection rate of high-concentration polymer solution, $Q$ $\mathrm{m}^{3} / \mathrm{d}$

$Q 2$ = injection rate of low-concentration polymer solution,

$h=$ reservoir thickness, $\mathrm{m}$

$r=$ radial distance, $\mathrm{m}$

$v=$ Darcy velocity, $\mathrm{m} / \mathrm{s}$

$R_{k}=$ permeability reduction coefficient

$K_{p}=$ effective permeability, $\mu \mathrm{m}^{2}$

IPV = inaccessible pore volume fraction

$\phi_{p}=$ effective porosity

$C_{p 0}=$ injection concentration of HPAM solution, $\mathrm{g} / \mathrm{L}$

$D=$ diffusion coefficient of HPAM, $\mathrm{cm}^{2} / \mathrm{s}$

erf $=$ error function

$t=$ seepage time, $\mathrm{s}$

$t_{1}=$ injection time of high-concentration polymer solution,

$\mathrm{d}$

$t_{2}=$ injection time of low-concentration polymer solution,

d

$p_{1}=$ pressure of the first zone, $\mathrm{MPa}$ 
$\phi_{1}=$ porosity of the first zone

$C_{t 1}=$ total compressibility of the first zone, $\mathrm{MPa}^{-1}$

$K_{1}=$ permeability of the first zone, $\mu \mathrm{m}^{2}$

$p_{2}=$ pressure of the second zone, $\mathrm{MPa}$

$\phi_{2}=$ porosity of the second zone

$C_{t 2}=$ total compressibility of the second zone, $\mathrm{MPa}^{-1}$

$K_{2}=$ permeability of the second zone, $\mu \mathrm{m}^{2}$

$p_{3}=$ pressure of the third zone, $\mathrm{MPa}$

$\phi_{3}=$ porosity of the third zone

$C_{t 3}=$ total compressibility of the third zone, $\mathrm{MPa}^{-1}$

$K_{3}=$ permeability of the third zone, $\mu \mathrm{m}^{2}$

$p_{i}=$ primitive oilfield pressure, $\mathrm{MPa}$

$p_{w f}=$ bottom hole pressure, $\mathrm{MPa}$

$C=$ wellbore storage coefficient, $\mathrm{m}^{3} / \mathrm{MPa}$

$B=$ volume factor of polymer solution

$B_{o}=$ volume factor of oil

$S=$ skin factor

$R_{m 1}=$ radius of the first zone, $\mathrm{m}$

$R_{m 2}=$ radius of the second zone, $\mathrm{m}$

$\mu_{p 1}=$ viscosity of low-concentration polymer solution in

the first zone, $\mathrm{mPa} \cdot \mathrm{s}$

$\mu_{p 2}=$ viscosity of high-concentration polymer solution in the second zone, $\mathrm{mPa} \cdot \mathrm{s}$

$\mu_{o}=$ crude oil viscosity in the third zone, $\mathrm{mPa} \cdot \mathrm{s}$

$p_{D}=$ dimensionless pressure

$p_{w D}=$ dimensionless bottom hole pressure

$t_{D}=$ dimensionless time

$C_{D}=$ dimensionless wellbore storage coefficient

$r_{D}=$ dimensionless distance

$r_{w}=$ wellbore radius, $\mathrm{m}$

$p_{w D}^{\prime}=$ derivative of dimensionless bottom hole pressure

$\Delta p_{w D}=$ difference of dimensionless bottom hole pressure

$\Delta t_{D}=$ difference of dimensionless time

$\mathrm{BHP}=$ bottom hole pressure

$\mathrm{CNPC}=$ China National Petroleum Corporation

\section{Acknowledgments}

The authors would like to acknowledge CNPC for providing experiment data and pressure analysis data. The authors appreciate the comments of editors and reviewers in preparing the manuscript.

Open Access This article is distributed under the terms and conditions of the Creative Commons Attribution (CC BY-NC-ND) license, which permits unrestricted use, distribution, and reproduction in any medium, provided the original work is properly cited.

\section{References}

Bera, A., Mandal, A., Guha, B.B. Synergistic effect of surfactant and salt mixture on interfacial tension reduction between crude oil and water in enhanced oil recovery. J. Chem. Eng. Data 2013, 59(1): 89-96.

Bondor, P.L., Hirasaki, G.J., Tham, M.J. Mathematical simulation of polymer flooding in complex reservoirs. SPE J. 1972, 12(5): 369-382.

Bourdet, D., Ayoub, J.A., Pirard, Y.M. Use of pressure derivative in well test interpretation. SPE Form. Eval.
1989, 4(2): 293-302.

Carreau, P.J. Rheological equations from molecular network theories. Madison, University of Wisconsin-Madison, 1968.

Farajzadeh, R., Ameri, A., Faber, M.J., et al. Effect of continuous, trapped, and flowing gas on performance of alkaline surfactant polymer (ASP) flooding. Ind. Eng. Chem. Res. 2013, 52(38): 13839-13848.

Flory, P.J. Principles of Polymer Chemistry. New York, USA, Cornell University Press, 1953.

Jamaloei, B.Y., Kharrat, R., Torabi, F. Analysis and correlations of viscous fingering in low-tension polymer flooding in heavy oil reservoirs. Energy Fuels 2010, 24(12): 63846392.

Lake, L.W. Enhanced Oil Recovery. Boston, USA, Prentice Hall, 1996.

Liu, J., Guo, Y., Hu, J., et al. Displacement characters of combination flooding systems consisting of gemininonionic mixed surfactant and hydrophobically associating polyacrylamide for Bohai offshore oilfield. Energy Fuels 2012, 26(5): 2858-2864.

Liu, Y., Yan, B., Zhai, Y., et al. Transient pressure behavior in a homogeneous composite reservoir. Acta Petrolei Sinica 1994, 15(1): 92-100. (in Chinese)

Meter, D.M., Bird, R.B. Tube flow of non-Newtonian polymer solutions: PART I. Laminar flow and rheological models. AIChE J. 1964, 10(6): 878-881.

Ren, G., Sanders, A.W., Nguyen, Q.P. New method for the determination of surfactant solubility and partitioning between $\mathrm{CO}_{2}$ and brine. J. Supercrit. Fluids 2014, 91: 77-83.

Ren, G., Zhang, H., Nguyen, Q.P. Effect of surfactant partitioning between $\mathrm{CO}_{2}$ and water on $\mathrm{CO}_{2}$ mobility control in hydrocarbon reservoirs. Paper SPE 145102 Presented at the SPE Enhanced Oil Recovery Conference, Kuala Lumpur, Malaysia, 19-21 July, 2011.

Shiran, B.S., Skauge, A. Enhanced oil recovery (EOR) by combined low salinity water/polymer flooding. Energy Fuels 2013, 27(3): 1223-1235.

Song, K. Well test analysis of a compound reservoir with non-Newtonian and Newtonian fluid flow. Acta Petrolei Sinica 1996, 17: 82-86. (in Chinese)

Song, K., Zhu, J. Well test analysis for a compound reservoir with non-Newtonian power-law fluids flow. Acta Petrolei Sinica 1997, 18: 78-83. (in Chinese)

Veerabhadrappa, S.K., Trivedi, J.J., Kuru, E. Visual confirmation of the elasticity dependence of unstable secondary polymer floods. Ind. Eng. Chem. Res. 2013, 52(18): 6234-6241.

Wang, J. Physic-Chemical Fluid Mechanics and Application in Chemical EOR. Beijing, Petroleum Industry Press, 2008. (in Chinese)

Wang, X. Determination of the main parameters in the numerical simulation of polymer flooding. Pet. Explor. Dev. 1990, 3: 69-76.

Wyatt, N.B., Gunther, C.M., Liberatore, M.W. Increasing viscosity in entangled polyelectrolyte solutions by the addition of salt. Polymer 2011, 52(11): 2437-2444. 
Yu, H., Guo, H., Cheng, S., et al. Numerical well testing interpretation method of composite model and applications in offshore reservoirs by polymer flooding. Asian J. Chem. 2014, 26(17): 5783-5788.

Yu, H., Kotsmar, C., Yoon, K.Y., et al. Transport and retention of aqueous dispersions of paramagnetic nanoparticles in reservoir rocks. Paper SPE 129887 Presented at the SPE Improved Oil Recovery Symposium, Tulsa, Oklahoma, USA, 24-28 April, 2010.

Zhang, H., Challa, R.S., Bai, B., et al. Using screening test results to predict the effective viscosity of swollen superabsorbent polymer particles extrusion through an open fracture. Ind. Eng. Chem. Res. 2010, 49(23): 1228412293.

Zhang, T., Murphy, M.J., Yu, H., et al. Investigation of nanoparticle adsorption during transport in porous media. SPE J. 2015, 20(4): 667-677.

Zhu, C., Cheng, S., He, Y., et al. Pressure transient behavior for alternating polymer flooding in a three-zone composite reservoir. Polym. Polym. Compos. 2017, 25(1): 1-10. 